\title{
A PICTORIAL FIELD GUIDE FOR THE RAPID IDENTIFICATION OF SANDFLTES (DIPTERA: PSYCHODIDAE), COMMONLY ENCOUNTERED IN PARÁ STATE, BRAZIL.
}

\author{
L. Ryan $(* *)$ \\ R. Lainson $(* *)$ \\ J. J. Shaw $(* *)$
}

\section{SUMMARY}

A pictorial field guide to the 30 species of sandfly most commonly encountered in Para State is presented, based on the easily recognised external characters of the length of the 5th palpal segment, thoracic infuscation, abdominal colour and head and body size. In most cases this allows identification to the species. In others, especially with females, it gives an indication of the species, which may then be confirmed with data from more detailed taxanomix studies. This type of field guide helps in teaching, rapid sorting of flies prior to dissection and in acquainting visitors with the variety of species present in a given area.

A rapid technique for the taxonomic sorting of unmounted, freshey killed female sandflies is required, prior to the dissection of large numbers of a particular species. Such a method is useful in areas where numerous species occur in studies on natural blagellate infections, age determination and for ecological studies. With the above points in mind a pictorial field guide has been designed that enables the identification of unmounted, unmacerated specimens of the 30 more commonly encountered species of phlebotomine sandflies (***) in Para State, North Brazil. It is based on the easily recognised external characters of the length of the 5th palpal segment, thoracic infuscation, addominal colour and proboscis and body size.

Taxonomy of male phlebotomine sandflies is based on the structure of the genitalia and, as most of this is external, a wholly external character key is readily made. Female taxonomy, however, is based on the internal characters of the cibarium, pharynx and sperma thecae. In order to produce an external character hey we therefore return to an unso phisticated "phlebotometry" (see Martins et al., 1978 p. 3 for review), using relative

(*) This work was carried out under the auspices of the WeI1come Trust (London) and the Instituto Evandro Chagas, Fundaçäo SESP, Belëm, Parä, Brazil.

(**) Wellcome Parasitology Unit, Instituto Evandro Chagas, Fundação SESP, CP. 3,Belëm, 66000 Parä, Brazil.

(***) Authorities for all phlebotomines mentioned in the text are given by Martins et a1. (1978). 
lengths of the proboscis, palpal segments and body, along with the degree of infuscation. This idea is not new; indeed many sandfly specialists presently use external characters to separate certain species $(H$. Fraiha, R. P. Lane, P. D. Ready, D. G. Young and R. D. Ward personal communications $1983 \& 19841$.

A key used to separate five anthropophillic sandflies by Biagi (1966), in Mexico, was based mainly on palpal segment length and infuscation. Floch and Abonnenc (1952) stressed the use of relative lengths of palpal segments in their keys to the sandflies of French Guiana, and four members of the shannoni group have been similarly separated according to the degree of infuscation by Morales et al. 11982). The use of thoracic infuscation as a reliable character seems to be gaining favour, having been used by young \& Fairchild (1974) and Ready \& Fraiha 1981). Indeed Chaniotis 1974) showed the usefulness of thoracic infuscation to seperate 7 anthropophillic species, during studies onvesicular stomatitis in panama. Identification using external characters is essential forwork on viral isolations from sandflies, where bulk samples of whole sandflies are used.

Perhaps the major advantage of a simple visual guide is for teaching purposes. Technical staff in this Institute are able to identify most of the species they encounter without having to use the standard, more unvieldly (and in many cases unavailable) internal character keys, and the guides presented below have allowed rapid species sorting prior to the dissection of sandflies in our leismaniasis study areas (Ryan et al., 1985).

\section{DISCUSSION}

This field guide to the sandflies of Para has been found to work during the period between June 1983 and December 1984, in our study sites of Marajö (Lainson et al., 1983) Belém (Lainson \& Shaw, 1968), Carajäs (Ward et al., 1973), Santarëm(Lainson et al.,1984 \& 1985), Tucurui, Porto Trombetas, Ruropölis, Presidente Médici and Paragominas. The phlebotomine fauna must first be studied in a given area; and a fieldguide for the common species may be produced which speeds the work rate and allows identification of the sandflies without mounting or maceration. Smaller samples may be examined in greater detail to check the validity of the identification made with the field guide.

We stress that this is not an alternative to the accepted characters in use at pre sent in the few available keys, but rather an aid to field work in a given region. Where for example, one already knows Ps. davisi to be present in a given work area the pictorial guide immediately reminds the field worker of its appearance. Again a relatively untrained dissector may give his opinion that a sandfly is Ps. davisi, and this can then be confirmed by the person of the dissecting team who is examining the spermathecae and guts.

In addition, for teaching purposes, this guide provides a useful starting point, or introducting to the sandflies of Parà. The small and medium 5 th palpal segment groups function well, fortunately, as most of the anthropophillic flies beiong to these groups. Even so difficulties may arise in separating Ps. amazonensis from Ps. claustrei and the 636

L. Ryan et al. 
Trichophoromyia subgenus generally. Within the series squamiventris it is at present impossible to separate female Ps. squamiventris squamiventris, Ps. s. maripaensis, Ps. complexus; Ps. chagasi and as yet undescribed members o the series found in Pará State: the males of these species, however, are all characteristic (Ready et al., 1982). Only Ps. wellcomei and Ps. complexus are figured in this guide as they are both present at our study site in the Serra dos Carajäs, where recent studies (Ryan et al., 1985) have confirmed without doubt that the former is the proven vector of Le. b. brasiliensis. We use Lu. guyanensis assuming that Lu. geniculata is the junior synonym. We use here Lu. trinidadensis although this may eventually prove to be Lu. villelai, should the latter be resurrected ( $H$. Fraiha personal communication, 1985).

The long 5 th palpal segment group contains many of the species that are encountered only as males and/or that are captured rarely. Anthropophilic species include Lu. gome $\mathbf{z i}$, Lu, carvalhoi and Lu. Iongipalpis, and these are all characteristic. It is dificult to distinguish between females of species in the subgenus Pressiata, as well as between Lu. dasypodogeton and Lu. longispina females. Another recent complication is the discovery of a Lu. longipalpis complex (Ward et al., 1985), where note must be made of the presence of one two abdominal, white spots on males.

All the characters used are constant, but caution should be exercised when dealing with Lu. longipalpis, as this species exhibits awide morphological range. A small, white form encountered in Camară, Marajö Islanơ and Santarém, Pará, is fortunately uncommon in our samples $(1=1000)$.

\section{ACKNOWLEDGEMENTS}

We are grateful to Dr. D. G. Young for his comments on the manuscript.

\section{RESUMO}

Eapresentado um "levantamento ilustrado" dos 30 flebotomineos mais comumente encontrados no Estado do Parä. Brasil, usando-se caracteristicas externas, com as medidas do quinto segmento das palpos, cor do tôrax e do abdomen, e medidas da cabeça e do corpo. Com isto é possivel, na maioria dos casos, levar à identificação até a espécie. Exis tem algumas espëcies, entretanto, que são mais dificeis de serem identificadas, particu larmente as fêmeas, havendo nestes casos, necessidade de um exame taxonômico mais detalhado, para que se possa concluir a identificação. Esta orientaçäo ilustrada $\vec{e}$ particu larmente ütil a técnicos de laboratörio, estudantes e entomölogos visitantes. 


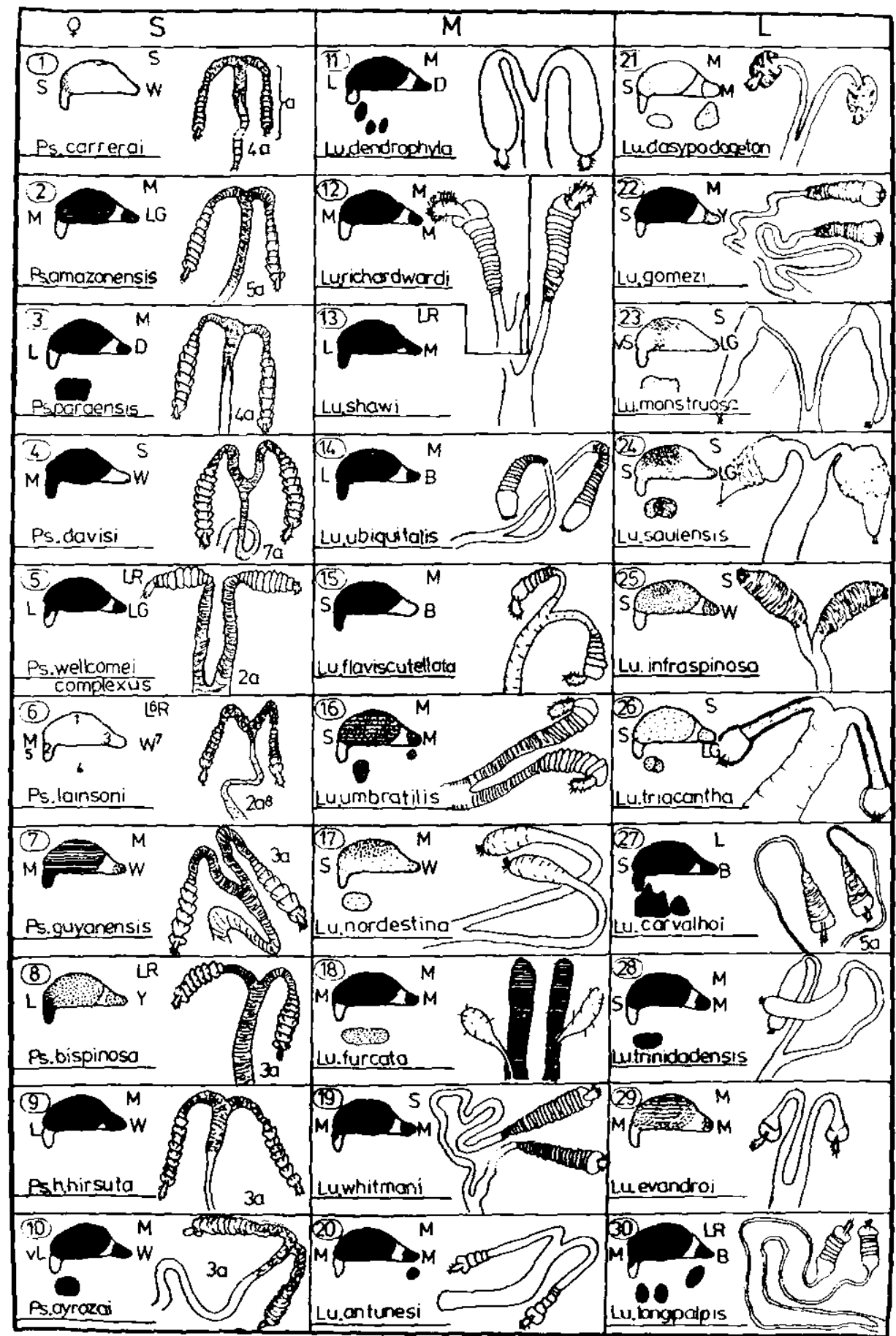

Fig. 1A. Field guide to the 30 most commonly encountered species of sandflies in Parä State, north Brazil.

A. Females.

I: The key - initially divides into 3 columns according to the relative length of the $5 \mathrm{th}$ palpal segment, where the ratio to the 5 th:4th:3rd segments is as follows:

$S$ (short) $5 t h=0.5 \times 3 r d=4 t h=$ genus Psychodopygus. 
cont. - Fig. 1A.

M (medium) $5 t h=3 r d=2 \times 4 t h \&<(3 r d+4 t h)=$ subgenera Viannamyia, Trichophoromyia, Nyssomyia, Psathyromyia and groups brasiliensis, lanei and driesbachi.

L (long) $5 \mathrm{th}=2 \times 3 \mathrm{rd}=3 \times 4 \mathrm{th} \&>(3 \mathrm{rd}+4 \mathrm{th})=\mathrm{all}$ other subgenera and groups.

II. Using number 6, Ps. lainsoni as an example: theleft figure indicates the degree of infuscation, represented by shading (increasing from white ; light ; medium \& ; to dark ), of 1 : scutum; 2: pronotum; 3 : scutellum; 4: sternopleuron.

The letters in the figures refer to:

5: Size of proboscis (from the clypeus to the tip)in proportion to:

the size of the antenna (shown as being equal in length to antennal segments $I$ to $\underline{\mathfrak{n}}$ ) and:

the size of the head (from read capsule o clypeus) thus:

vI (very long): $n=6:>$ head,

$L$ (long): $n=5:$ =head,

M (medium): $n \approx 4:=$ head,

S (short): $\mathrm{n}<4:<$ =head,

vS (very short): $\mathrm{n}<4: 0.6 \mathrm{x}$ head.

6: Overall size of the thorax and abdomen, excluding the head and male genitalia. This category is subjective in that the observer will consider Ps, wellcomei as a large fly, because of its long legs. However, as a guide we give the equivalent size in millimetres:

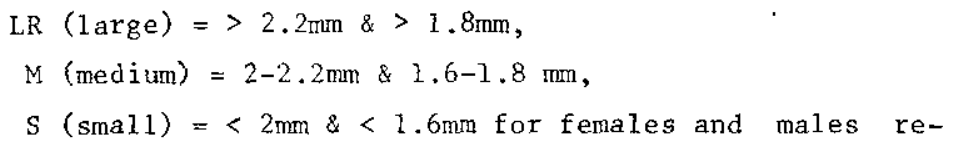
spective1y.

7: Colour of the abdomen where $W=$ white, $L G=1$ ight, $M=$ medium and $D=$ dark infuscation, $Y=$ yellow, $B=$ black.

8: When mounted or dissected the spermathecae (figured for each species) allow confirmation. Where (a) is the length of the spermathecal body, such that the common spermathecal duct is twice the length of (a) ie, 2a, 


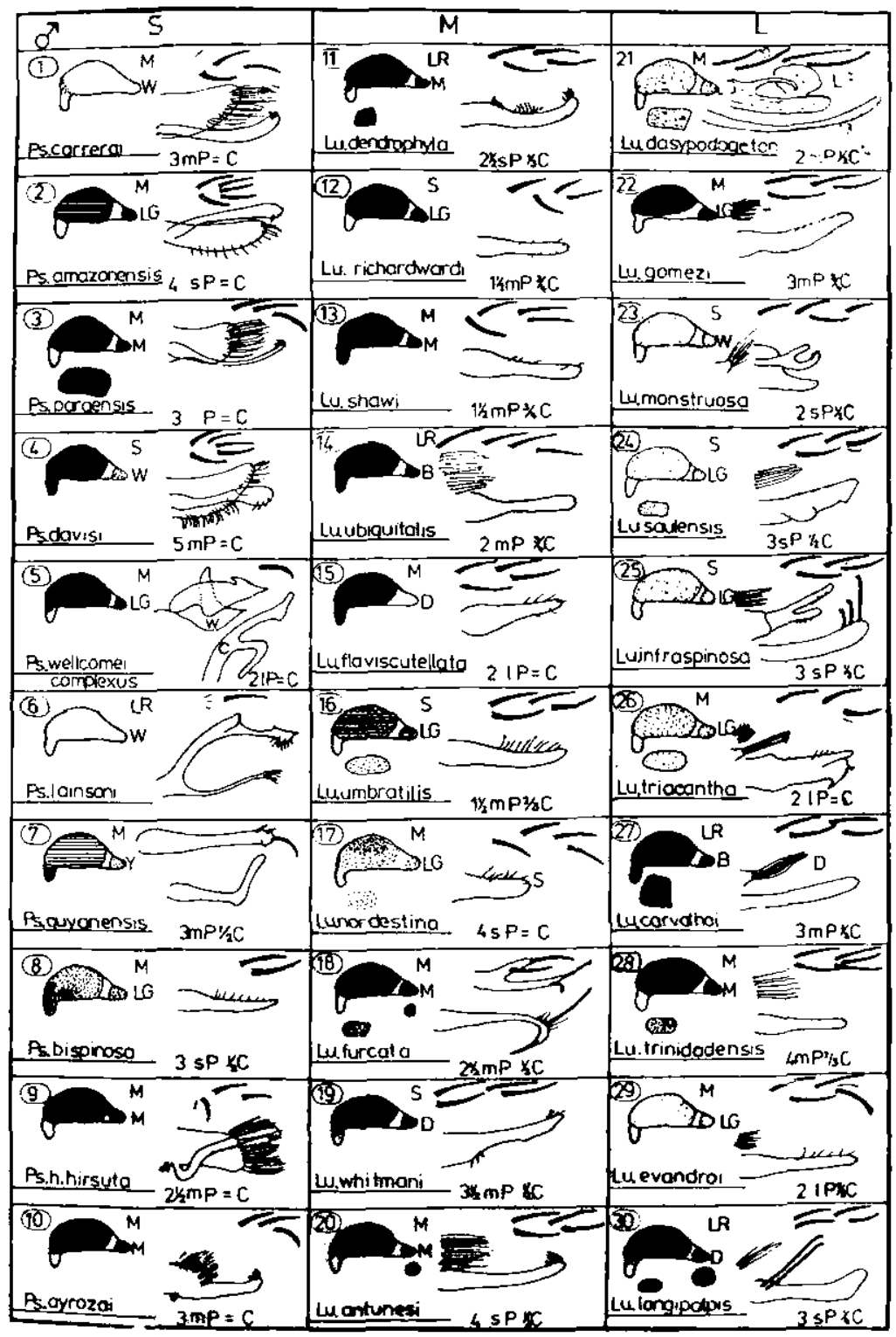

Fig. 1B. As for females with the additional parameters of: (as in examples $21 \mathrm{Lu}$. dasypodogeton and $22 \mathrm{Lu}$. goeexi).

B. Males.

9: The overall size of the genitalia, this is only used when obviously LR (large) or S (sma11).

10: The arrangement and number of spines on the style. 11: The presence or absence of a basal tuft.

12: The structure of the paramere and, in some cases, the 13: structure of the lateral lobe.

14: The formula $2 \mathrm{sPl} / 2 \mathrm{C}$ is such that the genital filaments are $2 x$ the length of the (s) small sized (P) pump which in turn is $1 / 2$ the length of the (C) coxite. It may be determined after mounting or dissection. 


\section{References}

Biagi, A. M. de B. de - 1966. Clave para identification rapida de las hembras de Phlebotomus anthropofilos del area endemica de Leishmaniasis cutanea en Mexico. Rev. Invest. Salud Publ. (Mex.), 26: 367-372.

Chaniotis, B. N. - 1974. Use of external characters for rapid identification phlebotomine sandflies in vector studies. J. Med. Ent., 11: 501.

Floch, H. \& Abonnenc, E, - 1952. Diptères Phlébotomes de 1a Guyane et des Antilles Fran caises. ORSTOM, Paris, 207 p.

Lainson, R. \& Shaw, J. J. - 1968. Leishmaniasis in Brazil: 1. Observations on enzootic rodent Leishmaniasis-incrimination of Lutzomyia flaviscutellata (Mangabeira) as the vector in the Lower Amazon. Trans. R. Soc. Trop. Med. \& Hyg., 62: 385-395.

Lainson, R.; Shaw, J. J.; Ryan, L.; Ribeiro, R. S. M.; Silveira, F. T. - 1984. Presente situaça da leishmaniose visceral na Anazōnia, com especial referēncia a um novo sur to da doença occorrido em Santarên, Estado do Parä, Brasil. Boletim Epidemilogico de SESP, No. Especial JuTho 1984.

Lairıson, R.; Shaw, J. J.; Ryan, L.; Ribeiro, R. S. M.; Silveira, F. T. - 1985 . Leishra niasis in Brazil. 21: Visceral Leishmaniais in the Amazon region and further observations on the role of Lutzomyja longipalpis (Lutz \& Neiva, 1912) as the vector. Trans. R. Soc. Trop. Med. \& Hyg. (in press).

Lainson, R.; Shaw, J. J.; Silveira, F. T. \& Fraiha, H. - 1983. Leishmaniasis in Brazil. 19: Visceral Leishmaniasis in the Amazon Region, and the presence of Lutzomyia longi palpis on the Island of Marajó, Pará State. Trans. R. Soc. Trop. Med. \& Hyg. 77:323330.

Martins, A. V.; Williams, P.; Falcão, A. L. - 1978. American Sandflies.Rio de Janeiro: Academia Brasileira de Ciencias, $195 \mathrm{p}$.

Morales, A.; Rodriguez, M. C. de; Ibagos, A. L. - 1982. Descripcion de la hembra de Lutzomyia scaffi (Damasceno \& Arouck, 1956) (Diptera, Psychodidae).Biomedica,2:17-21.

Ryan, L.; Lainson, R.; Shaw, J. J. - 1985. Leishmaniasis in Brazi1. XXIII: Natural, flagellate infections of sandflies (Diptera: Psychodidae) in Para State, with parti cular reference to the role of Psychodopygus wellcomei as the vector of Leishmaniasis brasiliensis brasiliensis in the Serra dos Carajäs. Trans.R.Soc.T.M. \& H. (in press).

Ready, P. D. \& Fraiha, H. - 1981. Brazilian Phlebotomines, 6: Lutzomyia richardwardi sp. n., a new species of Nyssomyia from Amazonia with keys for this subgenus (Diptera, Psychoddiae). Rev. Brasil. Biol., 41: 705-712.

Ready, P. D.; Fraiha, H.; Lane, R. P.; Arias, J. R.; Pajot, F. X. - 1982.0n distinguish ing the female of Psychodopygus wellcomei, a vector of mucocutaneos leishmaniasis, from other squamiventris series females 1. Characterization of Ps.squamiventris squa miventris and Ps. s. maripaensis stat. nov. (Diptera: Psychodidae) Ann. Trop. Mec. $\overline{\mathbb{8}}$ Parasit. $76: 201-214$.

Ward, R. D.; Ribeiro, A. L.; Ryan, L.; Falcão, A. L.; Range1, E. F. - 1985. The distribution of two morphological forms of Lutzomyia longipalpis (Lutz \& Neiva) (Diptera: Psychodidae). Mem. Inst, 0s. Cruz. (in press).

Ward, R. D.; Shaw, J. J.; Lainson, R.; Fraiha, H. - 1973. Leishmaniasis in Brazil. 8: observations on the Phlebotomine fauna of an area highly endemic for cutaneous Leish maniasis, in the Serra dos Carajās, Parä State. Trans.R.Soc.Trop.Med. \& Hyg.67:174-183. 
Young, D. G. \& Fairchild, G. B. - 1974. Studies on Phlebotomine sandflies. Annual Report 31 May 1984, Dept. Ent. Nemat., Uni. of Florida, U.S.A. 151 p.

(Aceito para publicaçäo em 26.11.1986) 